\title{
Conversion of laparoscopic cholecystectomy to open cholecystectomy in a single center
}

\begin{abstract}
Laparoscopic cholecystectomy (LC) has become the gold standard for the surgical treatment of gallbladder disease, but conversions to open cholecystectomy are still inevitable in certain cases. Knowledge about the rate and underlying reasons for conversion could help surgeons during preoperative assessment and improve the informed consent of patients. We decide to review the rate and causes of conversion of our LC series. This study included 320 consecutive laparoscopic cholecystectomies from January 2017 to December 2019 at Community Based Medical College Hospital Bangladesh, Mymensingh. All patients had surgery performed by same surgeon. Conversion to open cholecystectomy required in 15 $(4.6 \%)$ patients. Out of 15 cases, the highest number of patients $10(66.6 \%)$ were in age group 50 to 59 years with a mean age of 60.1 years and standard deviation (SD) of 9.8 years. Of them $9(60 \%)$ were male. The most common reasons for conversion of them were severe adhesions at calot's triangle 6 (40\%) and acutely inflamed gallbladder 5 (33.3\%), bleeding 2 $(13 \%)$. No surgical procedures are complication free. The most common complication was superficial wound infection $8(2.5 \%)$. Delayed complications seen in our series is port site incisional hernia $2(0.62 \%)$. Male gender, age older than 60 years, previous upper abdominal surgery, diabetes, and severity of inflammation were all significantly correlated with an increased conversion rate to laparotomy. LC is the preferred method even in difficult cases. This study emphasizes that although the rate of conversion to open surgery and complication rate are low in experienced hands, the surgeons should keep a low threshold for conversion to open surgery.
\end{abstract}

Biswas $\mathrm{SK}^{1}$, Roy $\mathrm{SR}^{2}$, Sarker $\mathrm{S}^{3}$, Rahman $\mathrm{MM}^{4}$, Islam $\mathrm{MK}^{5}$

CBMJ 2020 July: vol. 09 no. 02 P: 14-18

Key words: Laparoscopic cholecystectomy (LC), Open cholecystectomy, Conversion, Complications, Calot's triangle.

\section{Introduction}

Laparoscopic cholecystectomy (LC) was first reported in Germany (1985) and France (1987) more than four decades ago. Over the past two decades, laparoscopic cholecystectomy (LC) has become gold standard for the surgical treatment of gallbladder disease. A shorter hospital stay, less postoperative pain, faster recovery, better cosmesis are some of the advantages of LC over open surgery. ${ }^{1,2}$ The complications encountered during LC are numerous: some that are specific to this unique technique and some that are common to laparoscopic surgery in general. These include complications related to anesthesia; complications related to peritoneal access (e.g., vascular injuries, visceral injuries, and port-site hernia formation); complications related to pneumoperitoneum (e.g., cardiac complication, pulmonary complications, and gas embolism) and complications related to thermocoagulation. Specific complications of LC are gall bladder perforation, haemorrhage, bile leakage, bile duct injury, and wound sepsis, hematoma, foreign body inclusions, adhesions, metastatic port-site

1. Dr. Suttam Kumar Biswas, Asst. prof. Dept. of Surgery, Community Based Medical College, Mymensingh.

2. Dr. Shilpi Rani Roy, Lecturer, Dept. of Pharmacology, Mymensingh Medical College, Mymensingh.

3. Dr. Subbrata Sarker, Junior consultant, Dept. of Surgery, Fulbaria upozilla health complex.

4. Dr. Md. Mustafizur Rahman, Junior consultant, Dept. of Surgery, Valuka upozilla health complex.

5. Dr. Md. Kamrul Islam, Junior consultant,Dept. of ICU, Community Based Medical College Hospital, Mymensingh.

Address of correspondence:

Email: suttamkumarbiswas@gmail.com Mobile: 01711151452 
deposits. $^{3,4}$ Some of these complications and several other factors can necessitate the conversion from LC to open cholecystectomy. Approximately $75 \%$ of all cholecystectomies are performed laparoscopically, and conversion to the open procedure ranges from $4 \%$ to $10 \%$ nationwide. The conversion from LC to open cholecystectomy results in a significant change in outcome for the patient because of the higher rate of postoperative complications and the longer hospital stay. Outcome of LCs would be greatly influenced by surgeon-specific factors, such as training, experience, skill and judgment. In addition, numerous patient and diseaserelated factors, such as male gender, obesity, old age $(>60)$, prior abdominal surgery, acute cholecystitis, choledocholithiasis, and anomalous anatomy have been reported as significant risk factors for conversion to the open procedure. The initial rate of common bile duct (CBD) injury in LC ranged from $0.2 \%$ to $3 \%$, or up to 5 times higher than in OC., However, experience with LC and improved laparoscopic principles encouraging the accurate anatomical identification of structures, limited dissection within Calot's triangle, and the judicious use of intraoperative cholangiography have stabilized the CBD injury rate to a range of $0.25 \%$ to $0.5 \%$ nationwide. ${ }^{9}$ Furthermore, a 2006 Cochrane review declared there was no significant difference in morbidity, mortality, and operative time between LC and OC. ${ }^{12}$ More importantly, LC has been shown to have significant advantages over OC by reducing postoperative pain and thereby accelerating recovery and return to work and activity. ${ }^{8}$ Despite this progress, there are still a substantial proportion of patients in whom LC cannot be successfully performed and conversion to open surgery is required. This study retrospectively reviews LC series in this hospital and to compare the results with other reported literature.

\section{Materials and Methods:}

Data was collected retrospectively from hospital records of patient's profile of 320 patients with symptomatic gall bladder disease who underwent LC at Community Based Medical College Hospital, Mymensingh from January 2017 to December 2019. A routine history was taken from all patients presenting for treatment for symptomatic gallbladder disease and all underwent a physical examination, laboratory testing, and ultrasonographic examination of abdomen. Informed consent was obtained from all patients after the nature of the procedure and the possibility of the need for conversion from the laparoscopic approach to an open cholecystectomy was explained. Prophylactic antibiotic intravenously was given to all patients at induction of anaesthesia. All patients had surgery performed by same surgeon using standard four port techniques. The conversion rate to open cholecystectomy, the underlying reasons, and postoperative complications were recorded.

\section{Selection criteria:}

Inclusion criteria: All patients with gall stone disease and gall bladder polyp admitted in CBMCHB within the study period were included.

Exclusion criteria: Mucocele of gall the bladder, empyema gall bladder, neoplastic growth of the gall bladder were excluded.

\section{Results:}

Laparoscopic cholecystectomy was performed in 320 patients, out of them 273 $(85.3 \%)$ were female and $47(14.6 \%)$ were male with a mean age of 39.6 years (range 17-76 years). Ultrasonography demonstrated cholelithiasis in all the cases. All patients were evaluated on an elective basis and scheduled for surgery. Conversion to open cholecystectomy required in 15 (4.6\%) patients. Out of 15 cases, the highest number of patients $10(66.6 \%)$ were in age group 50 to 59 years with a mean age of 60.1 years and standard deviation (SD) of 9.8 years. 
Of them 9 (60\%) were male. The most common reasons for conversion of them were severe adhesions at calot's triangle 6 $(40 \%)$ and acutely inflamed gallbladder 5 (33.3\%), bleeding $2(13 \%)$. Less common causes of conversion were CBD injury $1(6.66 \%)$ and fibrotic gallbladder $1(6.66 \%)$.

Table I: Indications for conversion to open cholecystectomy $(n=15)$

\begin{tabular}{|l|c|c|}
\hline \multicolumn{1}{|c|}{ Indication for conversion } & Frequency & Percentage \\
\hline Dense adhesions at Calot's Triangle & 6 & 40 \\
\hline Acutely inflamed gallbladder & 5 & 33.3 \\
\hline Bleeding complication & 2 & 13 \\
\hline $\begin{array}{l}\text { Contracted small fibrotic adherent } \\
\text { gallbladder }\end{array}$ & 1 & 6.66 \\
\hline Common bile duct injury & 1 & 6.66 \\
\hline Total & $\mathbf{1 5}$ & $\mathbf{1 0 0 . 0}$ \\
\hline
\end{tabular}

\section{Discussions:}

The majority of cholecystectomies are performed laparoscopically now a days and it is the commonest operation performed laparoscopically worldwide. ${ }^{5}$ The conversion rate and complications associated with LC depend on the experience of the surgeon and degree of difficulty faced during surgery. Conversion to open cholecystectomy is not a complication, rather a matter of sound surgical judgment as patient safety. There are many studies in the literature concerning the conversion rate (range: $1.5 \%$ to $7.7 \%$ ). ${ }^{6-8}$ In this study, the conversion rate was determined to be $4.4 \%$, which compares favorably with the rates reported in the literature. Dense adhesions at the calot's triangle and acute cholecystitis are two of the most important reasons for conversion to open procedure, as was also shown in the present study. Dense adhesions at calot's triangle signified chronic inflammation and were certainly due to the repeated attacks of acute cholecystitis which makes very difficult identification of structures of calot's triangle. The conversion rates in acute cholecystitis were reported in the literature to reach up to $27.7 \%{ }^{9}$ In this series of 320 patients, only 16 patients having acute cholecystitis submitted for LC of which 5 (33.3\%) patients were converted which is consistence with other study. In case of acute cholecystitis conversion rate could be reduced by performing operation within 72 hours of onset of symptoms where tissue planes are oedematous which magnify the structures and facilitate dissection. After 72 hours, the tissue becomes increasingly frozen and friable which makes dissection at calot's triangle very risky and dangerous till 4-6 weeks' time when inflammation subsides and fibrosis sets in. ${ }^{10}$ Bleeding complication account for up to one third of all major complications seen in LC, and are the second most common cause of death in patients undergoing the procedure (after anaesthesia related complications). ${ }^{11,12}$ The reported incidence of uncontrollable bleeding in LC is $0.03-10 \% .^{12-16}$ This study $2(13 \%)$ cases were converted due bleeding complication, one from injury to cystic artery during dissection of calot's triangle and another from abnormal cystic artery. Both cases were managed well by prompt conversion, one required blood transfusion. Operative bile duct injury is one of the serious complications of hepatobiliary surgery. During surgical learning curve of LC there was an initial rise in the reports of bile duct injuries, resulting mainly from the surgeon's inexperience and misinterpretation of anatomy. ${ }^{17}$ Compared to open operation, injuries sustained during LC are often more severe (e.g., excision of a segment of the CBD) and generally extend to higher level. A recent audit of 1522 LCs performed in Thailand revealed a bile duct injury rate of $0.59 \%{ }^{18}$ In Jordan in 2001 , of 791 patients with chronic cholecystitis and 207 with acute cholecystitis who underwent LC, extra hepatic bile duct injuries were reported in only three cases. ${ }^{19}$ A Swedish study has shown that a surgeon is most likely to injure the bile duct when undertaking between his $25^{\text {th }}$ and $100^{\text {th }}$ laparoscopic cholecystectomy. Only one case was converted due bile duct injury (Case no 41, Common hepatic duct transection) which was detected intraoperatively and primarily repaired over a T-tube. 


\section{Conclusions:}

Laparoscopic cholecystectomy is one of the most commonly performed laparoscopic procedures. Problems during laparoscopic cholecystectomy include conversion to open cholecystectomy, bile duct injury, bleeding and other postoperative complications. Although there are several studies reporting various rates and their causes of conversion, every institution or surgeon must have a thorough understanding of the rate and causes of conversion to open surgery. Conversion from laparoscopic to open cholecystectomy should be based on the sound clinical judgment of the surgeon and not due to lack of individual expertise. Surgeons should lower their threshold for conversion to open cholecystectomy in these high-risk patients when laparoscopic difficulty begins to compromise patient safety.

Limitations: This study is a single centre. This type study should be carried on in large scale and nationwide.

Recommendations: Laparoscopic cholecystectomy should be done after proper case selection and surgeon should be trained and expertise.

\section{References:}

1. Biswas SK, Saha JC, Rahman ASMT, Rahman ASMZ, Rahman MM. Rate of Conversion and Postoperative Complications of Laparoscopic Cholecystectomy in District Level Hospital of Bangladesh.Faridpur Med. Coll. of Laparoscopic Cholecystectomy in District Level Hospital of Bangladesh.Faridpur Med. Coll. J. 2011;6(2):74-77.

2. Mir IS, Mohsin M, Kirmani O, Majid T, Wani K, Hasan MU, et al. Is intraoperative cholangigraphy necessary during laparoscopic cholecystectomy? A multicenter rural experience from a developing world country. World J Gastroenterol. 2007; 13:4493-7.

3. Ros A, Gustafsson L, Krook H, Nordgren CE, Thorell A, Wallin G, et al. Laparoscopic Cholecystectomy versus mini-laparotomy Cholecystectomy: a prospective, randomized, single blinded study. Ann surg. 2001; 234:7419.
4. Deziel DJ, Millikan KW, Economou SG, Doolas A, Ko ST, Airan MC. Complications of LC: A national survey of 4292 hospitals and an analysis of 77604 cases. Am J Surg. 1993; 165:9-14.

5. Bittner R. Laparoscopic surgery: 15 years after clinical introduction. World J surg. 2006; 30:1190-203.

6. Tayeb M, Raza SA, Khan MR, Azami R. Conversion from laparoscopic to open cholecystectomy: Multivariate analysis of preoperative risk factors. J Postgrad Med.2005; 51:234-8.

7. Ghnnam W, Malek J, Shebl E, Elbeshry T, Ibrahim $A$. Rate of conversion and complications of laparoscopic cholecystectomy in a tertiary care center in Saudi Arabia. Ann Saudi Med. 2010;30(2):145-8.

8. Genc V, Sulaimanov M, Cipe G, Basceken SI, Erverdi $N$, Gurel $M$, et al. What necessitates the conversion to open cholecystectomy? A retrospective analysis of 5164 consecutive laparoscopic operations. Clinics 2011;66(3):417-20.

9. Kim KR, Ibrahim S, Tan NC, Lim SH, Tay KH. Risk factors for conversion to open surgery in patients with acute cholecystitis undergoing interval laparoscopic cholecystectomy. Ann Acad Med Singapore 2007; 36:631-5.

10. Biswas SK, Saha JC, Rahman MM, Rahman MA. Laparoscopic cholecystectomy in acute calculus cholecystitis-Experience at district level hospital. Faridpur Med Coll J. 2010; 5(1):3-6.

11. Mases A, Montes A, Ramos R, Trillo L, Puig $M M$. Injury to the abdominal aorta during laparoscopic surgery: an unusual presentation. Anesth Analg. 2000; 91:561-2.

12. Gharaibeh KI, Ammari $F$, Al-Heiss $H, A l-$ Jaberi TM, Qasaimeh GR, Bani-Hani K, et al. Laparoscopic cholecystectomy for gallstones.Ann Saudi Med. 2001; 21:312-6.

13. Singh $R$, Kaushik $R$, Sharma $R$, Attri $A K$. Non-biliary mishaps during laparoscopic cholecystectomy. Ind J Gastroenterol. 2004; 23:47-9. 
Original Article

14. Kaushik R. Bleeding complications in laparoscopic cholecystectomy: Incidence, mechanisms, prevention and management. J Minim Access Surg. 2010; 6(3):59-65.

15. Sicklick JK, Camp MS, Lillemoe KD, Melton GB, Yeo CJ, Campbell KA, et al. Surgical management of bile duct injuries sustained during laparoscopic cholecystectomy. Ann Surg. 2005; 241:786-95.

16. Andrén-Sandberg A, Alinder G, Bengmark $S$. Accidental lesions of the common bile duct at cholecystectomy. Pre- and perioperative factors of importance. Ann Surg. 1985; 201:328-32.

17. Huang $Z Q$, Huang $X Q$. Changing patterns of traumatic bile duct injuries: A review of forty years' experience. World J Gastroenterol. 2002; 8:5-12.

18. Vagenas K, Karamanakos SN, Spyropoulos $C$, Panagiotopoulos $S$, Karanikolas $M$, Stavropoulos M. Laparoscopic Cholecystectomy: A report from a single center. World JGastroenterol. 2006; 12:3887-90.

19. Morgenstern L, Berci G, Pasternak EH. Bile leak after biliary tract surgery: $A$ laparoscopic perspective. Surg Endosc. 1993; 7:432-8. 